\title{
Coupled Ocean-Atmosphere Variations over the South Atlantic Ocean
}

\author{
Paulo Nobre, Roberto A. De Almeida, Marta Malagutti, \\ AND EMANUEL GIAROLLA \\ National Institute for Space Research (INPE), Cachoeira Paulista, Brazil
}

(Manuscript received 10 August 2011, in final form 1 March 2012)

\begin{abstract}
The impact of ocean-atmosphere interactions on summer rainfall over the South Atlantic Ocean is explored through the use of coupled ocean-atmosphere models. The Brazilian Center for Weather Forecast and Climate Studies (CPTEC) coupled ocean-atmosphere general circulation model (CGCM) and its atmospheric general circulation model (AGCM) are used to gauge the role of coupled modes of variability of the climate system over the South Atlantic at seasonal time scales. Twenty-six years of summer [DecemberFebruary (DJF)] simulations were done with the CGCM in ensemble mode and the AGCM forced with both observed sea surface temperature (SST) and SST generated by the CGCM forecasts to investigate the dynamics/thermodynamics of the two major convergence zones in the tropical Atlantic: the intertropical convergence zone (ITCZ) and the South Atlantic convergence zone (SACZ). The results present both numerical model and observational evidence supporting the hypothesis that the ITCZ is a thermally direct, SSTdriven atmospheric circulation, while the SACZ is a thermally indirect atmospheric circulation controlling SST variability underneath - a consequence of ocean-atmosphere interactions not captured by the atmospheric model forced by prescribed ocean temperatures. Six CGCM model results of the Ensemble-based Predictions of Climate Changes and their Impacts (ENSEMBLES) project, NCEP-NCAR reanalysis data, and oceanic and atmospheric data from buoys of the Prediction and Research Moored Array in the Tropical Atlantic (PIRATA) Project over the tropical Atlantic are used to validate CPTEC's coupled and uncoupled model simulations.
\end{abstract}

\section{Introduction}

Summer rainfall distribution over most of tropical South America is strongly modulated by two atmospheric convergence zones: the South Atlantic convergence zone (SACZ) (Carvalho et al. 2004; Lenters and Cook 1999; Liebmann et al. 1999; Nogués-Paegle and Mo 1997) and the intertropical convergence zone (ITCZ) (Chang et al. 2000; Hastenrath and Lamb 1977). Notwithstanding the fact that both zones have a pronounced maritime component, they present fundamental dynamical differences. The ITCZ lies over warmer surface waters, its variability is modulated by the underneath meridional gradient of sea surface temperatures (SSTs) (Chiang et al. 2002; Nobre et al. 2006), and it is generally well simulated by global atmospheric general circulation models (AGCMs) forced by prescribed SST

Corresponding author address: Paulo Nobre, National Institute for Space Research (INPE), Cachoeira Paulista, SP, 12630-000, Brazil.

E-mail: paulo.nobre@cptec.inpe.br
(Chang et al. 2000). Contrasting with the ITCZ, the oceanic portion of the SACZ occurs predominantly over cooler surface waters (Grimm 2003; Robertson and Mechoso 2000) and is poorly simulated by AGCMs (Marengo et al. 2003; Nobre et al. 2006). AGCM studies of the behavior of the SACZ predict the formation of enhanced rainfall over warmer waters (Barreiro et al. 2002, 2005; Robertson et al. 2003) — an essentially hydrostatic response of the model atmosphere to positive SST anomalies. A comparison of results of 14 coupled ocean-atmosphere general circulation models (CGCMs) used for the Intergovernmental Panel on Climate Change (IPCC) Fourth Assessment Report (AR4) (Lin et al. 2009) shows that most of the models underestimate seasonal (November-April) mean precipitation over eastcentral and northeastern Brazil. They also fail to properly represent the SACZ and shift the ITCZ southward of its observed position during the Southern Hemisphere summer.

Several studies have demonstrated the importance of ocean-atmosphere coupling in explaining SST principal modes of variability over the tropical Atlantic (Chang 
et al. 2001; Huang et al. 2004; Nobre et al. 2003; Xie et al. 1999; Zebiak 1993), as well as the occurrence of SACZ rainfall (Chaves and Nobre 2004; De Almeida et al. 2007) and Asian-Pacific summer monsoon rainfall (Wang et al. 2005) over colder waters. Chaves and Nobre (2004) suggested a causal relationship between SACZ and SST, with the former conditioning the latter through solar radiation-cloud-SST feedback; cold SST anomalies under the SACZ are a consequence of the very formation of the SACZ, rather than the forcing mechanism that explains it. The use of a state-of-the-art AGCM to simulate summer rainfall globally generates patterns of rainfall distribution over southeastern South America and the southwestern tropical Atlantic that are negatively correlated to observed rainfall (Marengo et al. 2003; Nobre et al. 2006). This is a result commonly found in other two-tier AGCM approaches (i.e., first, a global SST forecast field is generated, and then the SST forecast is prescribed as a surface boundary condition of the AGCM), which generate thermally direct circulation cells with increased precipitation over warmer SSTs (Barreiro et al. 2005; Robertson et al. 2003). An alternative to the two-tier approach is the CGCMs' one-tier approach, which accounts for nonlinear effects of surface fluxes of momentum, water, and heat in determining SST and salinity variations.

A regionally coupled ocean-atmosphere experiment with the Center for Ocean-Land-Atmosphere Studies' (COLA) CGCM over the tropical Atlantic (Huang et al. 2002, 2004) demonstrated that the SST patterns that explain the largest variance of SST anomalies over the tropical Atlantic can be simulated by the coupled model without the need for external forcing, such as those emerging from the tropical Pacific Ocean during the occurrence of El Niño-Southern Oscillation (ENSO) episodes. These results suggest that the most recurrent patterns of SST anomalies over the tropical Atlantic can be explained by air-sea interactions within the Atlantic Ocean region or by the oceanic responses to atmospheric internal forcing. In fact, there are indications that Atlantic SST interhemispheric variations influence not only the Atlantic ITCZ variability, but also the North Atlantic Oscillation (NAO) and ENSO phenomena (Wu et al. 2007). Conversely, other studies indicate that both the interhemispheric SST gradient and the ENSO-related east-west Walker circulation modulate the variability of the Atlantic ITCZ (Chiang et al. 2002). The importance of local ocean-atmosphere coupling in explaining recurrent modes of sea surface temperature anomaly (SSTA) variability over the tropical Atlantic was also suggested by other studies (Chang et al. 1998; Kitoh et al. 1999; Nobre et al. 2003; Xie et al. 1999; Zebiak 1993), which used coupled ocean-atmosphere models of intermediary complexity to study modes of coupled variability of the tropical Atlantic and Pacific SST. Kitoh et al. (1999) showed that both latent heat flux and shortwave radiation (SWR) have their roles in producing SST anomalies in the equatorial Pacific Ocean.

Carvalho et al. (2004) presented observational evidence that SACZ variability over the southwestern Atlantic is related to midlatitude wave train activity. Other studies have indicated that the coupling between the atmosphere and ocean in the midlatitudes enhances the variance in both media, while it decreases the energy flux between the atmosphere and the ocean (Barsugli and Battisti 1998). The basic question of whether or not a coupled model is mandatory for simulating climate patterns like the NAO is addressed in the work of Bretherton and Battisti (2000), who showed that SSTforced AGCM simulations reproduce observed lowfrequency variability of the NAO, despite the simulated air-sea fluxes being of reverse sign to those observed. The misrepresentation of the local relationship between SST and precipitation by SST-prescribed AGCM simulations has also been shown to occur over parts of the Indian Ocean (Kumar and Hoerling 1998; Kumar et al. 2005). Other studies have suggested the role of continental surface-atmosphere feedbacks in explaining South American summer rainfall variations (e.g., Grimm 2003; Grimm et al. 2007).

Yet, the dynamics of the SACZ, whose preferred mode of variability shows enhanced precipitation over colder waters, persists as an outstanding question regarding seasonal climate variability and predictability over the southern tropical Atlantic Ocean. This paper explores the topic of coupled ocean-atmosphere processes from a fully coupled ocean-atmosphere global model point of view, with a focus on the dynamics of rainfall-SST relationships over the tropical Atlantic Ocean.

\section{Experiment design}

The Brazilian Center for Weather Forecast and Climate Studies' (CPTEC) coupled ocean-atmosphere general circulation model uses the Geophysical Fluid Dynamics Laboratory's (GFDL's) Flexible Modular System (FMS) coupler to couple CPTEC's AGCM to GFDL's Modular Ocean Model (MOM4p1) (Griffies 2010). CPTEC's AGCM is a spectral model with triangular truncation at wavenumber 62 , equivalent to approximately $1.875^{\circ} \times 1.875^{\circ}$ latitude-longitude horizontal resolution, and 28 sigma levels unevenly distributed in the troposphere between the surface and the lower stratosphere. The AGCM's physical parameterizations 
include solar (Davies 1982; Lacis and Hansen 1974) and terrestrial (Harshvardhan et al. 1987) radiation schemes. Deep convection is parameterized by Grell's (1993) scheme, while shallow convection is parameterized by the scheme of Tiedtke (1984). Mellor and Yamada's (1982) level-2.0 closure scheme is used for the turbulent transport of moisture, momentum, and heat in the atmospheric planetary boundary layer. The continental surface scheme is the Simplified Simple Biosphere (SSIB) model (Xue et al. 1991). The National Oceanic and Atmospheric Administration (NOAA)/GFDL's MOM4p1 is a primitive equation model configured over the globe, with a constant $1^{\circ}$ spacing in longitude and $1 / 4^{\circ}$ spacing in the latitudinal direction in the deep tropics $\left(10^{\circ} \mathrm{S}-10^{\circ} \mathrm{N}\right)$, decreasing uniformly to $1^{\circ}$ at $45^{\circ}$ and to $2^{\circ}$ at $90^{\circ}$ of both hemispheres. For the vertical axis, 50 levels are adopted, with a 10-m resolution in the upper $220 \mathrm{~m}$. The model uses an explicit free-surface formulation (Griffies 2010) and is fully coupled without flux correction each 2-hourly coupled time steps. The AGCM component sends to the coupler the freshwater, specific humidity, heat and momentum fluxes, surface pressure, and cosine of the zenith angle; the AGCM receives SST and ocean albedo from the CGCM flux coupler.

Ten-member ensembles for both CGCM and AGCM are done starting each model run from initial conditions (ICs) taken one day apart during 1-10 November for each year in the period 1981-2007, with December-February (DJF) as the target forecast period. Atmospheric ICs are taken from the National Centers for Environmental Prediction-National Center for Atmospheric Research (NCEP-NCAR) reanalysis (Kalnay et al. 1996), while oceanic ICs are taken from a 30-yr-long MOM4p1 spinup run forced by atmospheric fluxes of momentum and heat [Coupled Ocean-Ice Coordinated Ocean Research Experiments (CORE) version 2 from Large and Yeager (2009)]. Two sets of SST fields are used to generate the AGCM hindcasts: one is the optimum interpolation SST (OISST) from NCEP (Reynolds et al. 2002), which is used for each of the 10 members of the AGCM runs. The other set is the CGCM SST forecasts (CMSST) computed for this work. For this case, each member of the AGCM runs is forced by the SST forecast of the respective CGCM run (i.e., started from the same atmospheric IC). Both the OISST and CMSST used as boundary conditions for the AGCM hindcasts are monthly means, which are linearly interpolated to the day of integration by the AGCM. Model-output climatological fields are computed as the 1981-2007 long-term mean for each forecast month. Monthly anomalies are obtained by removing the monthly mean of each member for DJF.
Annual integrations from the Ensemble-based Predictions of Climate Changes and their Impacts (ENSEMBLES) Stream 2 project (Van der Linden and Mitchell 2009) are used to validate the CGCM model output, consisting of nine-member ensemble hindcasts integrated using six coupled models: (i) the Integrated Forecast System/Hamburg Ocean Primitive Equation (IFS/HOPE), used for seasonal forecasts at the European Centre for Medium-Range Weather Forecasts (ECMWF); (ii) the decadal prediction system (DePreSys) of the Met Office; (iii) Action de Recherche Petite Echelle Grande Echelle/Océan Parallélisé (ARPEGE4/ OPA), used for seasonal forecasts at Meteo-France; (iv) ECHAM5/OM1, used for seasonal forecasts at the Leibniz-Institut für Meereswissenschaften (IFMGEOMAR) at Kiel; (v) ECHAM5/OPA8.2, the seasonal forecast model used at the Istituto Nazionale di Geofisica e Vulcanologia (INGV) in Bologna; and (vi) the Hadley Centre Global Environmental Model version 2 (HadGEM2) from the Met Office. The integrations are 14-month hindcasts starting on 1 November of each year from 1960 to 2005. NCEP-NCAR reanalysis atmospheric vertical velocity-omega at $500 \mathrm{hPa}$ and shortwave solar radiation at the surface are used to validate the models' outputs. Rainfall data used for precipitation forecast skill evaluation are from the Global Precipitation Climatology Project (GPCP) for the period 1979-2007. The GPCP rainfall data are the result of a merged analysis that incorporates precipitation estimates from low-orbit satellite microwave data, geosynchronous-orbit satellite infrared data, and surface rain gauge observations (Adler et al. 2003; Huffman et al. 2009). The Prediction and Research Moored Array in the Tropical Atlantic (PIRATA; Bourlès et al. 2008) Project's daily buoy data of surface air temperature (SAT), SST, downwelling shortwave radiation, and rainfall are used to independently validate the model results. The PIRATA buoys of the southwestern extension were first moored in September 2005 (Bourlès et al. 2008), therefore the buoy time series consisted of 90 daily data points per DJF season for the years 2005-10, totaling 450 data points. Anomalies were computed as departures from the daily climatological values normalized by the local standard deviation. Both climatological time series were smoothed by a 30-day running mean to remove higher-frequency variability.

A Monte Carlo analysis was conducted on the anomaly cross-correlation (ACC) maps in order to estimate their statistical significance, accounting for the increased number of degrees of freedom due to the ensemble members. For each variable, 100 random datasets were created by shuffling triplets of DJF of each of the 10 ensemble members, resulting in 100 random ensembles with 


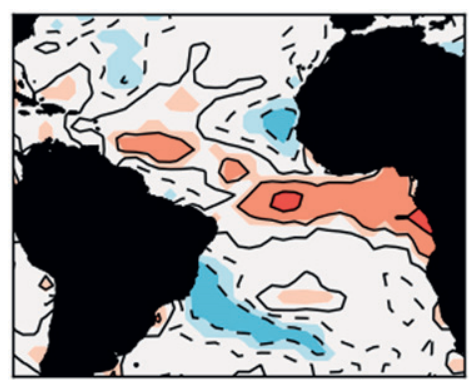

observations

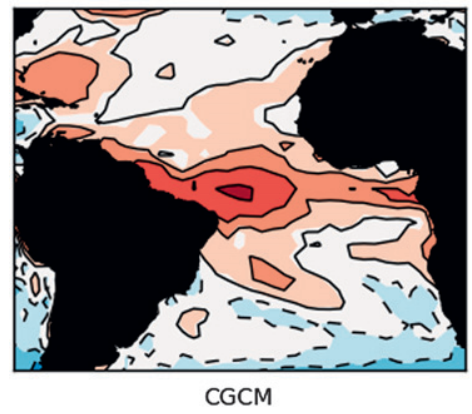

FIG. 1. DJF SST and rainfall ACC maps for (top left) observations, and 10-member ensemble means for (top right) rainfall hindcast from CPTEC AGCM forced with OISST, (bottom left) CPTEC CGCM rainfall forecast, and (bottom right) rainfall forecast from CPTEC AGCM forced with CMSST forecast, with the respective SST fields used to force the AGCM or product of the CGCM itself. Shaded areas depict values statistically significant at the $95 \%$ level.
10 members each. Inside each year the order of DJF triplets was maintained to ensure that the test accounted for month-to-month persistence of the data. The cross correlation was then repeated on the random datasets and averaged through each Monte Carlo ensemble. Statistical significance was assessed by comparing the absolute values of the averaged cross correlations from the original data with the correlations from the shuffled Monte Carlo members.

\section{Results}

\section{a. Simulating $S A C Z$ thermally indirect circulation}

Figure 1 shows DJF ACC maps between rainfall and SST for observations and both CGCM and AGCM simulations. The ACC was calculated separately for each of the 10 members for each model and was later averaged. Two main aspects are noteworthy in Fig. 1: (i) the statistically significant negative correlation patterns over the oceanic areas for both observations (Fig. 1a) and the coupled model forecasts (Fig. 1c) over the southwestern Atlantic, under the region of formation of the SACZ; and (ii) that both AGCM hindcasts forced with either OISST (Fig. 1b) or CMSST (Fig. 1d) show predominantly positive, statistically significant, rainfallSST ACC over the ocean. This result suggests that the
AGCM two-tier approach cannot correctly represent SACZ rainfall over cooler SSTs. The enhanced rainfall over warmer waters, regardless of whether the forcing SST field originates from observations or the coupled model forecast itself, is an inherent characteristic of the forced problem, a common behavior found in other AGCM model studies (Marengo et al. 2003; Robertson et al. 2003).

To verify whether the enhanced ability of CPTEC's CGCM to simulate precipitation over cold waters as shown in Fig. 1 is an inherent capability also present in other coupled models, the correlation analysis between DJF rainfall and SST was repeated using hindcasts from the ENSEMBLES Stream 2 project (Van der Linden and Mitchell 2009) multimodel ensemble. The cross correlation was calculated separately for each of the $6 \times$ 9 members. The cross correlation was later averaged for each model in order to assess its ability to reproduce the observed negative correlation between SST and rainfall in the SACZ region shown in Fig. 1. While all six coupled models are able to generate enhanced precipitation over anomalously cold water, the strength and location of the negative precipitation-SST correlations varies between models (Fig. 2). In particular, the HadGEM2 and ECHAM5/OPA8.2 models display a strong signal over the oceanic SACZ. 
IFS/HOPE

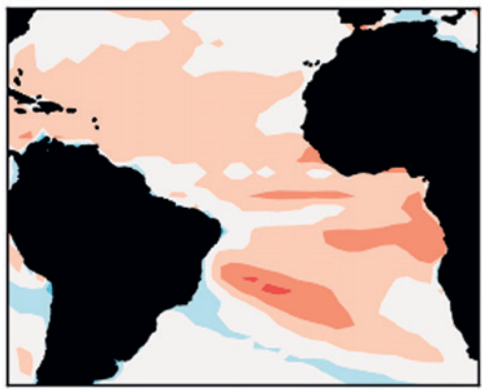

ECHAM5/OPA8.2

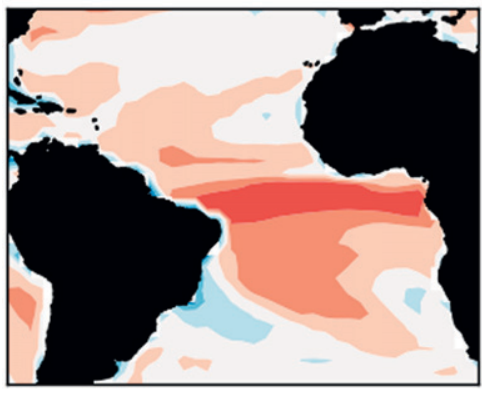

ARPEGE4/OPA

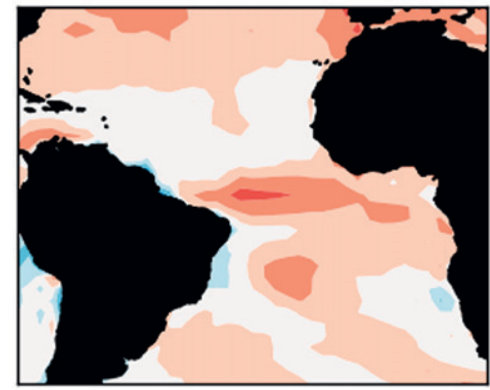

ECHAM5/OM1

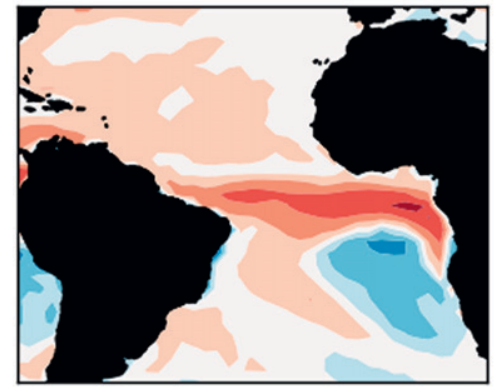

HadGEM2

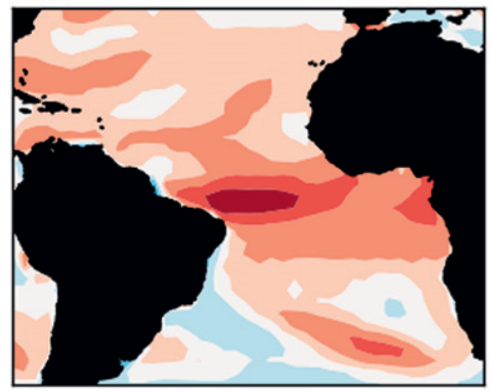

DePreSys

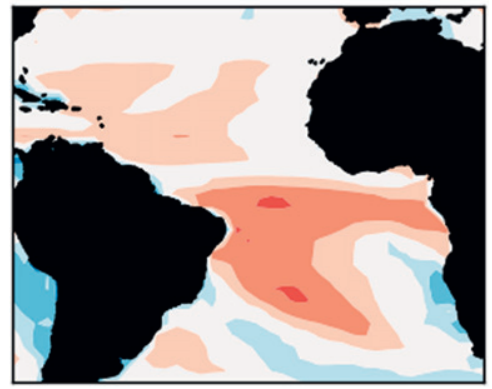

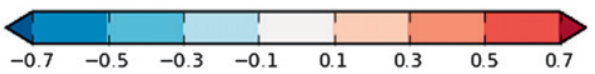

FIG. 2. DJF ACC maps between SST and rainfall anomalies for coupled ocean-atmosphere models: (top left) IFS/HOPE, (top middle) ARPEGE4/OPA, (top right) HadGEM2, (bottom left) ECHAM5/OPA8.2, (bottom middle) ECHAM5/OM1, and (bottom right) DePreSys. Shaded values represent correlations with a statistical significance of $95 \%$; nonsignificant values are masked as white.

Lending further support to the claim that rainfall over cooler waters over the southwestern Atlantic is a coupled ocean-atmosphere process, the ACC maps between SST and downward SWR are shown in Fig. 3. CGCM results (Fig. 3c) reproduce the pattern of positive SST-SWR ACC under the SACZ shown by observations (Fig. 3a), correctly representing the observed patterns of reduced (enhanced) downward solar radiation over cooler (warmer) waters. The AGCM results, on the other hand, depict negative correlations over most of the southwestern Atlantic, for both OISST(Fig. 3b) and CMSST-forced (Fig. 3d) runs, indicating an essentially direct thermally driven response of the atmosphere to SST forcing, with reduced (enhanced) solar radiation over warm (cooler) waters (i.e., enhanced cloudiness over warm waters and clear skies over cooler waters) over the SACZ area. Note also in Fig. 3 the predominance of negative ACC over the equatorial Atlantic, indicating that the direct thermally driven circulation related to the ITCZ shown in observations (Fig. 3a) is captured by both AGCM and CGCM simulations alike.

The contrasting thermal coupling conditions associated with the SACZ and ITCZ are also seen in the ACC maps for SST and omega at $500 \mathrm{hPa}$ shown in Fig. 4. Both observations and CGCM depict positive correlations over the southwestern Atlantic, as a result of ascending (descending) motion associated with negative (positive) SST over the SACZ area (i.e., a thermally indirect circulation), while both AGCM simulations show predominantly negative correlations, indicating the occurrence of ascending (descending) motion over warm (cool) waters for both the ITCZ and SACZ areas (i.e., a thermally direct circulation pattern).

\section{b. Validation with PIRATA data}

To further scrutinize the nature of the ocean-atmosphere coupling mechanism over the southwestern tropical Atlantic, independent time series of surface daily PIRATA buoy data (SAT, SST, downwelling SWR, and rainfall) are used. The chosen buoy sites are at $8^{\circ} \mathrm{S}, 30^{\circ} \mathrm{W}$ and $19^{\circ} \mathrm{S}, 34^{\circ} \mathrm{W}$, which correspond to regions of positive and negative rainfall-SST ACC (shown in Figs. 1a,c for observations and coupled model results, respectively). Positive ACC between SAT and SST over both sites (see Table 1) indicates the state of temperature equilibrium of the ocean-atmosphere interface on monthly time scales. The negative correlations between SWR and rain 


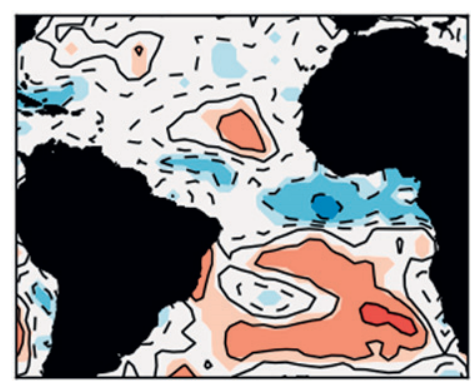

observations

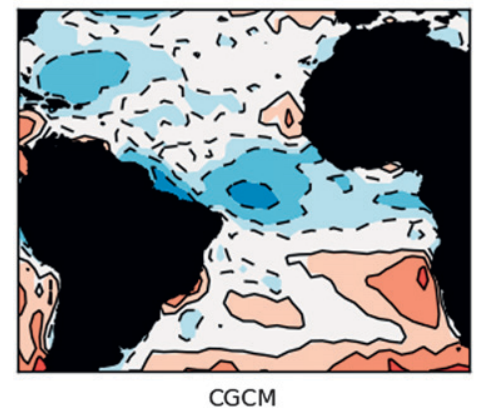

FIG. 3. As in Fig. 1, but for SST and downward SWR at the surface.

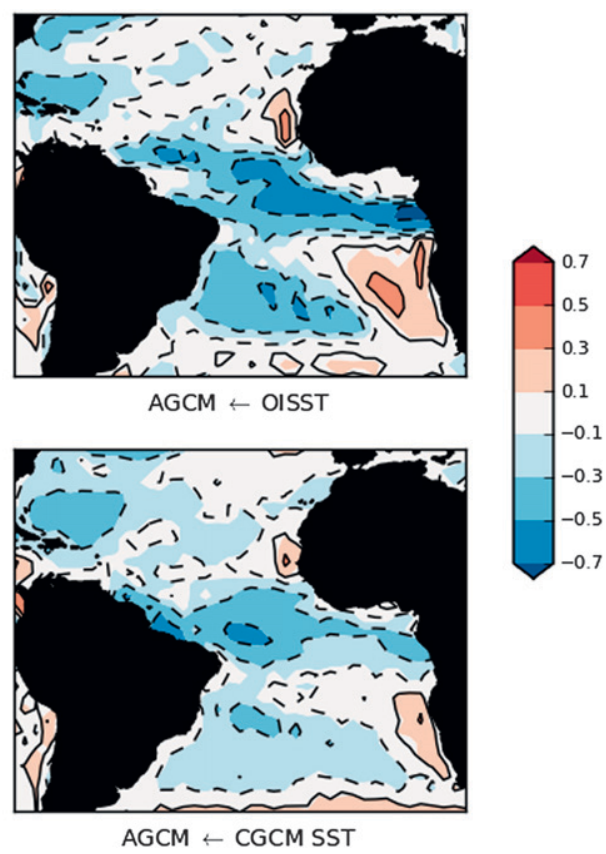

(clear) sky over the $19^{\circ} \mathrm{S}, 34^{\circ} \mathrm{W}$ buoy site. Similarly, ACC between rainfall and both SAT and SST shows increased (decreased) rainfall over a warmer (cooler) surface at the $8^{\circ} \mathrm{S}, 30^{\circ} \mathrm{W}$ buoy site, and increased (decreased) rainfall over a colder (warmer) surface at the $19^{\circ} \mathrm{S}, 34^{\circ} \mathrm{W}$ site. Together these results are coherent with the coupled model simulations, showing that the rainfall
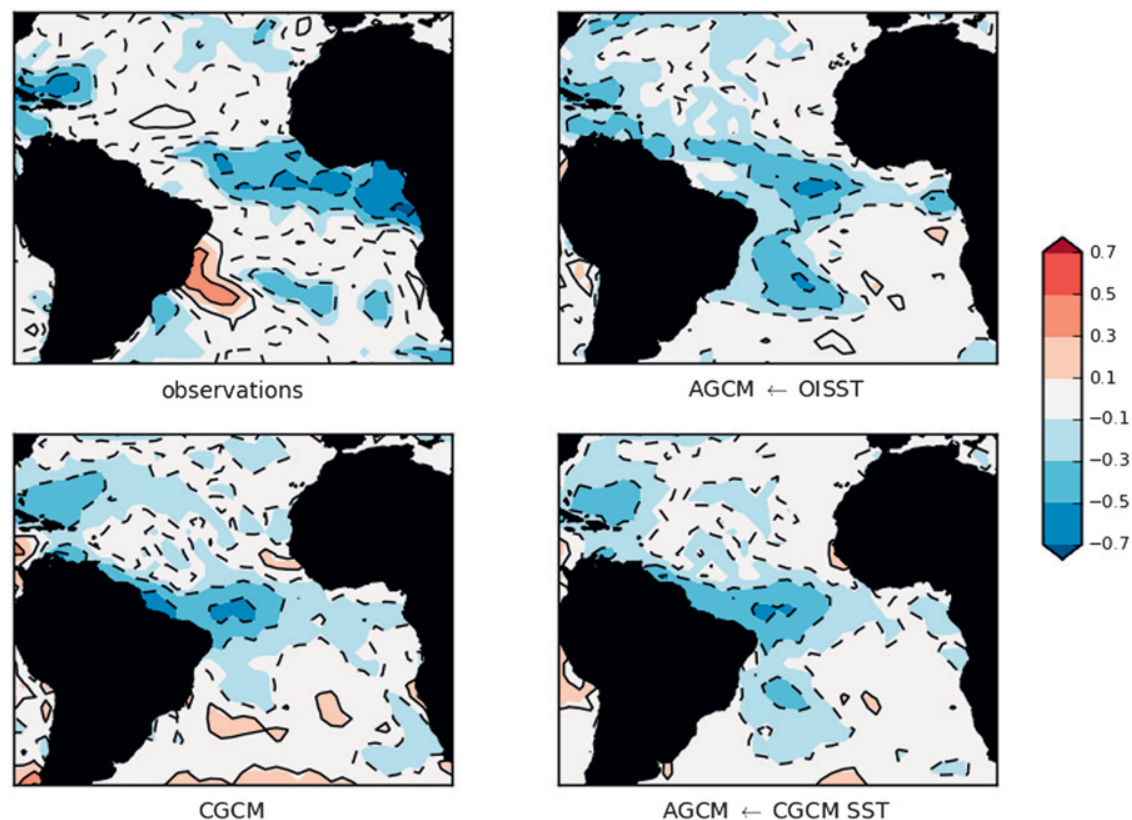

FIG. 4. As in Fig. 1, but for SST and omega at $500 \mathrm{hPa}$. 
TABLE 1. ACCs between surface air temperature (SAT), sea surface temperature (SST), rainfall (PREC), and downward shortwave radiation (SWR) for the PIRATA buoys at $8^{\circ} \mathrm{S}, 30^{\circ} \mathrm{W}$ and $19^{\circ} \mathrm{S}, 34^{\circ} \mathrm{W}$. Daily values smoothed with a 30 -day-runningmean filter for the DJF periods of 2005-10, totaling 450 pairs of data for each time series. Cross-correlation values greater than 0.35 (italic) $[0.6$ (boldface) $]$ are statistically significant at the $90 \%(99 \%)$ level according to a one-sided Student's $t$ test with 15 degrees of freedom.

\begin{tabular}{lcc}
\hline \hline Cross correlation & Buoy at $8^{\circ} \mathrm{S}, 30^{\circ} \mathrm{W}$ & Buoy at $19^{\circ} \mathrm{S}, 34^{\circ} \mathrm{W}$ \\
\hline SAT-SST & $\mathbf{0 . 9 1}$ & $\mathbf{0 . 9 4}$ \\
SWR-PREC & $-\mathbf{0 . 6 4}$ & $-\mathbf{0 . 7 4}$ \\
SAT-SWR & -0.38 & 0.49 \\
SST-SWR & -0.18 & 0.41 \\
SAT-PREC & 0.56 & -0.32 \\
SST-PREC & 0.33 & -0.19 \\
\hline
\end{tabular}

regime closer to the equator is thermally direct, with surface temperature conditions modulating rainfall, while the rainfall regime over the southwestern Atlantic is thermally indirect, with warmer surface conditions modulated by atmospheric solar radiation.

\section{c. Rainfall forecast skill}

Despite the better representation of the observed relations between SST and solar radiation and vertical velocities shown in Figs. 3, 4 by the CGCM, relative to the AGCMs, the results are only marginally statistically significant over the area of the SACZ. Yet, one could expect that the more physically sound representation of the SACZ dynamics and thermodynamics by the CGCM can leave its imprint on rainfall predictability over the southwestern Atlantic. Figure 5 shows DJF rainfall hindcast skill as measured by ACC between observed and simulated rainfall. The AGCM runs forced by OISST (Fig. 5a) depict the same robust correlation pattern of positive correlations along the equatorial area and negative correlations over the SACZ area, reproducing previous results that used AGCMs forced by observed SSTs to simulate the SACZ (Nobre et al. 2006; Robertson et al. 2003). It is noteworthy, however, that the strong negative ACC shown for the AGCM runs forced by observed SST is drastically reduced on the ACC map for the AGCM forced by CMSST (Fig. 5b) and is slightly positive for the CGCM forecasts (Fig. 5c). This is an indication that while monthly summer rainfall is still not skillfully predicted by the CGCM over the SACZ area, it represents an improvement relative to the systematic negative AGCM rainfall forecast skill over this area, as shown in Fig. 5d by the residual between the CGCM (Fig. 5c) and the AGCM OISST hindcast (Fig. 5a) ACC. On the other hand, Fig. 5d also shows the large CGCM forecast skill decrease over the equator, relative to the OISST-forced AGCM result, which is possibly

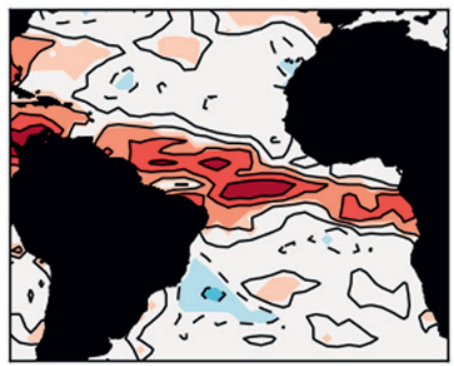

$\mathrm{AGCM} \leftarrow$ OISST

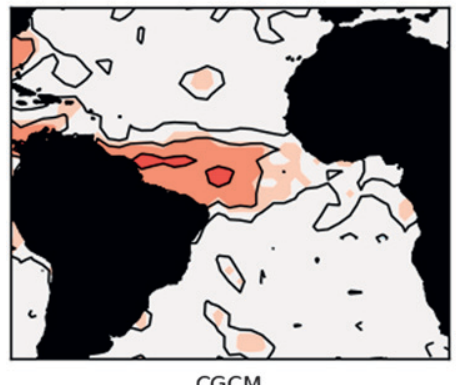

FIG. 5. DJF ACC maps between observed and forecast rainfall for 10-member-ensemble CPTEC (top left) AGCM forced by observed SST, (top right) AGCM forced by CGCM SST forecast, (bottom left) CGCM, and (bottom right) difference between (bottom left) and (top left). Shaded values in (top left), (top right), and (bottom left) represent correlations with a statistical significance of $95 \%$.

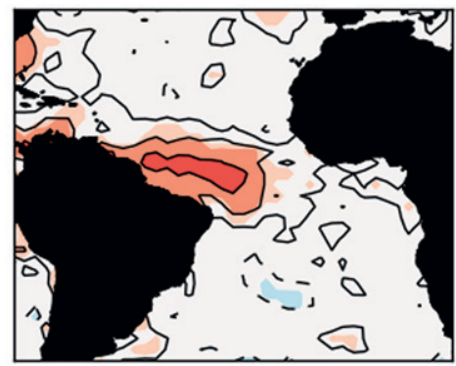

$\mathrm{AGCM} \leftarrow \mathrm{CGCM} \mathrm{SST}$

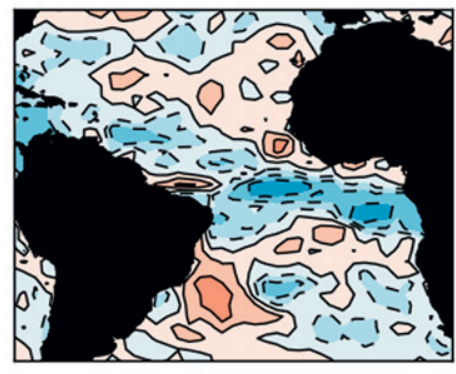

CGCM - (AGCM - OISST)

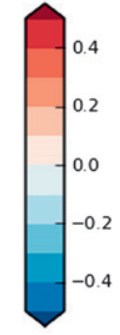


associated with the CGCM's systematic southward shift of the ITCZ relative to observations, and also documented in other CGCMs (Lin et al. 2009). In light of the coupled nature of ocean-atmosphere interactions over the SACZ region discussed above, the negative AGCM rainfall forecast skill over the SACZ area can be interpreted as a consequence of the AGCM's inability to represent thermally indirect circulation patterns in the atmosphere, which requires coupled ocean-atmosphere interactions at the surface. Yet, imperfections of the component models' physics create errors, which are allowed to grow during the coupling process, thus creating basic states of both the atmosphere and the oceans that are unrealistic relative to observations, and that end up degrading coupled-model rainfall forecast skill.

\section{Conclusions}

The dynamics and thermodynamics of DJF seasonal rainfall over the tropical Atlantic are investigated using both coupled ocean-atmosphere and atmospheric general circulation models, with special emphasis on the documented characteristic of enhanced rainfall associated with the South Atlantic convergence zone over cooler waters. The main result of this investigation highlights the ability of the coupled model to represent precipitation processes over cold waters of the tropical Atlantic, which sharply contrasts with the AGCM's inability to generate enhanced rainfall over cold waters. These results were already shown over the IndianPacific summer monsoon regime (Kumar et al. 2005; Wang et al. 2005). The sets of AGCM experiments forced with both observed SST and CGCM SST have demonstrated that the inability of the AGCM to simulate enhanced rainfall over cooler waters is a consequence of the lack of surface thermodynamic coupling in the AGCM runs. The rainfall-SST negative correlations of all ENSEMBLES coupled-model outputs over the southwestern tropical Atlantic also indicated that this is a general characteristic not only found with the CPTEC coupled model.

The analysis of anomaly cross-correlation fields between SST and rainfall, shortwave solar radiation, and 500-hPa vertical velocity discussed in this note forms the basis for a coherent set of dynamic/thermodynamic evidence lending robust numerical modeling support to the claim that the SACZ activity constitutes a thermally indirect ocean-atmosphere coupled mode of variability. The use of surface meteorological PIRATA buoy data provided independent observational validation of the model results, supporting the claim that the ability of the coupled ocean-atmosphere model to simulate the rainfall regime of the $\mathrm{SACZ}$, with convection occurring over colder waters, is not chance but the consequence of atmospheric radiative fluxes modulating surface temperatures. This, in turn, attests to the importance of solar radiation-clouds-SSTA negative feedback interactions associated with the SACZ dynamics, previously proposed by Chaves and Nobre (2004) and De Almeida et al. (2007) and documented by Robertson and Mechoso (2000) and Grimm (2003).

Yet, notwithstanding the robust implications of the CGCM correct representation of the thermally indirect circulation associated with the SACZ dynamics, which the AGCM was unable to represent, the CGCM onetier rainfall forecast skill was only enough to correct for the strong negative forecast skill generated by the AGCM for the area of the SACZ. Therefore, one practical consequence of this study is the realization that the use of coupled ocean-atmosphere models is necessary to predict summer rainfall over regions like the southwestern tropical Atlantic; nevertheless, further developments of the coupled-model physics are necessary to obtain usable rainfall forecasts in the future.

The importance of this result lies in the implication that the use of two-tier approaches is ill-suited for rainfall predictions in regions where the atmosphere modulates surface temperature, as is the case for the SACZ region. Both the coupled model and its atmospheric component model capture the occurrence of thermally direct atmospheric circulation with enhanced rainfall over warmer surface waters. Yet, systematic errors in the ocean thermal structure of the coupled model hinder the correct representation of the Atlantic warm pool over the western portion of the basin and the cold tongue over the eastern equatorial Atlantic. This is an intrinsic problem of most global coupled oceanatmosphere models, whose genesis might be linked with continental precipitation deficiencies over Africa and South America, as suggested by Richter and Xie (2008). The coupled ocean-atmosphere interactions over the equatorial Atlantic and its continental rainfall connection are being evaluated in another article led by the first author of this manuscript.

Acknowledgments. The authors acknowledge Dr. C. A. Nobre, Dr. B. N. Goswami, and the anonymous reviewers' comments and suggestions, which helped to sharpen the focus of this article. This work was partially funded by FAPESP under Contract 2005/00915-2 and Rede CLIMA. Special thanks to Mr. M. Baptista for conducting the model runs at CRAY XT6 supercomputer at INPE. The figures of this paper were computed with Python programming language. 


\section{REFERENCES}

Adler, R. F., and Coauthors, 2003: The Version-2 Global Precipitation Climatology Project (GPCP) Monthly Precipitation Analysis (1979-present). J. Hydrometeor., 4, 1147-1167.

Barreiro, M., P. Chang, and R. Saravanan, 2002: Variability of the South Atlantic convergence zone simulated by an atmospheric general circulation model. J. Climate, 15, 745-763.

$\ldots, \ldots$, and — 2005: Simulated precipitation response to SST forcing and potential predictability in the region of the South Atlantic convergence zone. Climate Dyn., 24, 105-114.

Barsugli, J. J., and D. S. Battisti, 1998: The basic effects of atmosphereocean thermal coupling on midlatitude variability. J. Atmos. Sci., $\mathbf{5 5}, 477-493$.

Bourlès, B., and Coauthors, 2008: The PIRATA Program: History, accomplishments, and future directions. Bull. Amer. Meteor. Soc., 89, 1111-1125.

Bretherton, C. S., and D. S. Battisti, 2000: An interpretation of the results from atmospheric general circulation models forced by the time history of the observed sea surface temperature distribution. Geophys. Res. Lett., 27, 767-770.

Carvalho, L. M. V., C. Jones, and B. Liebmann, 2004: The South Atlantic convergence zone: Intensity, form, persistence and relationships with intraseasonal to interannual activity and extreme rainfall. J. Climate, 17, 88-118.

Chang, P., C. Penland, L. Ji, L. Matrosova, and H. Li, 1998: Prediction of tropical Atlantic sea surface temperature. Geophys. Res. Lett., 25, 1193-1196.

_ , R. Saravanan, L. Ji, and G. C. Hegerl, 2000: The effect of local sea surface temperatures on atmospheric circulation over the tropical Atlantic sector. J. Climate, 13, 2195-2216.

_ L. L. Ji, and R. Saravanan, 2001: A hybrid coupled model study of tropical Atlantic variability. J. Climate, 14, 361-390.

Chaves, R. R., and P. Nobre, 2004: Interactions between sea surface temperature over the South Atlantic Ocean and the South Atlantic Convergence Zone. Geophys. Res. Lett., 31, L03204, doi:10.1029/2003GL018647.

Chiang, J. C. H., Y. Kushnir, and A. Giannini, 2002: Deconstructing Atlantic Intertropical Convergence Zone variability: Influence of the local cross-equatorial sea surface temperature gradient and remote forcing from the eastern equatorial $\mathrm{Pa}-$ cific. J. Geophys. Res., 107, 4004, doi:10.1029/2000JD000307.

Davies, R., 1982: Documentation of the solar radiation parameterization in the GLAS climate models. NASA Tech. Memo. $83961,57 \mathrm{pp}$

De Almeida, R. A. F., P. Nobre, R. J. Haarsma, and E. J. D. Campos, 2007: Negative ocean-atmosphere feedback in the South Atlantic Convergence Zone. Geophys. Res. Lett., 34, L18809, doi:10.1029/2007GL030401.

Grell, G. A., 1993: Prognostic evaluation of assumptions used by cumulus parameterizations. Mon. Wea. Rev., 121, 764 787.

Griffies, S. M., 2010: Elements of MOM4p1. GFDL Ocean Group Tech. Rep. 6, NOAA/Geophysical Fluid Dynamics Laboratory, $444 \mathrm{pp}$.

Grimm, A. M., 2003: The El Niño impact on the summer monsoon in Brazil: Regional processes versus remote influences. J. Climate, 16, 263-280.

- J. S. Pal, and F. Giorgi, 2007: Connection between spring conditions and peak summer monsoon rainfall in South America: Role of soil moisture, surface temperature, and topography in eastern Brazil. J. Climate, 20, 5929-5945.
Harshvardhan, R. Davies, D. A. Randall, and T. G. Corsetti, 1987: A fast radiation parameterization for atmospheric circulation models. J. Geophys. Res., 92 (D1), 1009-1016.

Hastenrath, S., and P. J. Lamb, 1977: Climatic Atlas of the Tropical Atlantic and Eastern Pacific Oceans. University of Wisconsin Press, 113 pp.

Huang, B., P. S. Schopf, and Z. Pan, 2002: The ENSO effect on the tropical Atlantic variability: A regionally coupled model study. Geophys. Res. Lett., 29, 2039, doi:10.1029/ 2002GL014872.

_ - _ and J. Shukla, 2004: Intrinsic ocean-atmosphere variability of the tropical Atlantic Ocean. J. Climate, 17, 20582077.

Huffman, G. J., R. F. Adler, D. T. Bolvin, and G. Gu, 2009: Improving the global precipitation record: GPCP Version 2.1. Geophys. Res. Lett., 36, L17808, doi:10.1029/2009GL040000.

Kalnay, E., and Coauthors, 1996: The NCEP/NCAR 40-Year Reanalysis project. Bull. Amer. Meteor. Soc., 77, 437-471.

Kitoh, A., T. Motoi, and H. Koide, 1999: SST variability and its mechanism in a coupled atmosphere-mixed layer ocean model. J. Climate, 12, 1221-1239.

Kumar, A., and M. P. Hoerling, 1998: Specification of regional sea surface temperatures in atmospheric general circulation model simulations. J. Geophys. Res., 103 (D8), 8901-8907.

Kumar, K. K., M. P. Hoerling, and B. Rajagopalan, 2005: Advancing dynamical prediction of Indian monsoon rainfall. Geophys. Res. Lett., 32, L08704, doi:10.1029/2004GL021979.

Lacis, A. A., and J. Hansen, 1974: A parameterization for the absorption of solar radiation in the earth's atmosphere. J. Atmos. Sci., 31, 118-133.

Large, W., and S. Yeager, 2009: The global climatology of an interannually varying air-sea flux data set. Climate Dyn., 33, 341-364.

Lenters, J. D., and K. H. Cook, 1999: Summertime precipitation variability over South America: Role of the large-scale circulation. Mon. Wea. Rev., 127, 409-431.

Liebmann, B., G. N. Kiladis, J. A. Marengo, T. Ambrizzi, and J. D. Glick, 1999: Submonthly convective variability over South America and the South Atlantic convergence zone. J. Climate, 12, 1877-1891.

Lin, J.-L., T. Shinoda, B. Liebmann, T. Qian, W. Han, P. Roundy, J. Zhou, and Y. Zheng, 2009: Intraseasonal variability associated with summer precipitation over South America simulated by 14 IPCC AR4 coupled GCMs. Mon. Wea. Rev., 137, 2931-2954.

Marengo, J. A., and Coauthors, 2003: Ensemble simulation of regional rainfall features in the CPTEC/COLA atmospheric GCM. Skill and predictability assessment and applications to climate predictions. Climate Dyn., 21, 459-475.

Mellor, G. L., and T. Yamada, 1982: Development of a turbulence closure model for geophysical fluid problems. Rev. Geophys. Space Phys., 20, 851-875.

Nobre, P., S. E. Zebiak, and B. P. Kirtman, 2003: Local and remote sources of tropical Atlantic variability as inferred from the results of a hybrid ocean-atmosphere coupled model. Geophys. Res. Lett., 30, 8008, doi:10.1029/2002GL015785.

— J. A. Marengo, I. F. A. Cavalcanti, G. Obregon, V. Barros, I. Camilloni, N. Campos, and A. G. Ferreira, 2006: Seasonalto-decadal predictability and prediction of South American climate. J. Climate, 19, 5988-6004.

Nogués-Paegle, J., and K. C. Mo, 1997: Alternating wet and dry conditions over South America during summer. Mon. Wea. Rev., 125, 279-291. 
Reynolds, R. W., N. A. Rayner, T. M. Smith, D. C. Stokes, and W. Wang, 2002: An improved in situ and satellite SST analysis for climate. J. Climate, 15, 1609-1625.

Richter, I., and S.-P. Xie, 2008: On the origin of equatorial Atlantic biases in coupled general circulation models. Climate Dyn., 31, 587-598.

Robertson, A. W., and C. R. Mechoso, 2000: Interannual and interdecadal variability of the South Atlantic convergence zone. Mon. Wea. Rev., 128, 2947-2957.

— J. D. Ferrara, and C. R. Mechoso, 2003: Simulations of the atmospheric response to South Atlantic sea surface temperature anomalies. J. Climate, 16, 2540-2551.

Tiedtke, M., 1984: The sensitivity of the time mean large-scale flow to cumulus convection in the ECMWF model. Proc. Workshop on Convection in Large-Scale Numerical Models, Reading, United Kingdom, ECMWF, 297-316.

Van der Linden, P., and J. F. B. Mitchell, 2009: ENSEMBLES: Climate change and its impacts: Summary of research and results from the ENSEMBLES project. Met Office Hadley Centre Rep., 160 pp. [Available online at http://ensembles-eu. metoffice.com/docs/Ensembles_final_report_Nov09.pdf.]

Wang, B., Q. Ding, X. Fu, I.-S. Kang, K. Jin, J. Shukla, and F. Doblas-Reyes, 2005: Fundamental challenge in simulation and prediction of summer monsoon rainfall. Geophys. Res. Lett., 32, L15711, doi:10.1029/2005GL022734.

Wu, L., F. He, Z. Liu, and C. Li, 2007: Atmospheric teleconnections of tropical Atlantic variability: Interhemispheric, tropicalextratropical, and cross-basin interactions. J. Climate, 20, 856870.

Xie, S.-P., Y. Tanimoto, H. Noguchi, and T. Matsuno, 1999: How and why climate variability differs between the tropical Atlantic and Pacific. Geophys. Res. Lett., 26, 1609-1612.

Xue, Y., P. J. Sellers, J. L. Kinter, and J. Shukla, 1991: A simplified biosphere model for global climate studies. J. Climate, 4, 345-364.

Zebiak, S. E., 1993: Air-sea interaction in the equatorial Atlantic region. J. Climate, 6, 1567-1586. 
Copyright of Journal of Climate is the property of American Meteorological Society and its content may not be copied or emailed to multiple sites or posted to a listserv without the copyright holder's express written permission. However, users may print, download, or email articles for individual use. 